\title{
CONSTRUCCIÓN DE SENTIDOS Y TENSIONES ENTRE CIUDADES VECINAS ALREDEDOR DE UN MURO: EL CASO DE POSADAS (MISIONES, ARGENTINA) Y ENCARNACIÓN (ITAPÚA, PARAGUAY)
}

\author{
CONSTRUÇÃO DE SENTIDOS E TENSÕES ENTRE CIDADES \\ VIZINHAS AO REDOR DE UM MURO: O CASO DE POSADAS \\ (MISIONES, ARGENTINA) E ENCARNACIÓN (ITAPUA, PARAGUAY)
}

\author{
CONSTRUCTION OF SENSES AND TENSIONS BETWEEN \\ NEIGHBORING CITIES AROUND A WALL: THE CASE OF POSADAS \\ (MISIONES, ARGENTINA) AND ENCARNACIÓN (ITAPUA, \\ PARAGUAY)
}

Ana Belén MEDINA ${ }^{1}$

\begin{abstract}
Resumen: El Estado construye y da sentido al poder de diferentes maneras, una de ellas es situando "en los márgenes" a ciertos territorios que componen la jurisdicción nacional y planificando el ordenamiento territorial al interior de los mismos. Desde esta perspectiva, el controvertido proyecto de ordenamiento del tránsito en la zona fronteriza ejecutado por el Estado Nacional Argentino, el Estado Provincial de Misiones y la Entidad Binacional Yacyretá, iniciado en 2014, consistió en la construcción de un muro de hormigón de $5 \mathrm{~m}$. de alto y $300.000 \mathrm{~m}$. de largo en las orillas del río Paraná (Posadas); generando una línea arquitectónica entre la población asentada en la zona céntrica y el borde costero donde se localiza el control aduanero. Entendemos a esta iniciativa como una acción disciplinadora, venida desde el estado, generadora de un impacto directo en las relaciones fronterizas y locales entre y en las ciudades vecinas de Posadas (Misiones, Argentina) y Encarnación (Paraguay). Entonces, nos preguntamos: ¿Qué sentido tendría ese muro para esas sociedades que habitan estas espacialidades fronterizas? La mirada desde lo regional/local nos permitirá observar, entonces las distintas formas de consolidación del poder y del control del Estado al interior de dichas territorialidades.
\end{abstract}

Palabras claves: Frontera; Muro; Posadas (Misiones); Encarnación (Paraguay).

Resumo: O Estado constrói e dá sentido ao poder de diferentes maneiras, uma delas é colocar "à margem" certos territórios que compõem a jurisdição nacional e planejar o planejamento territorial dentro deles. Nessa perspectiva, o polêmico projeto de planejamento de trânsito na área de fronteira executado pelo Estado Nacional da Argentina, pelo Estado Provincial de Missões e pela Entidade Binacional Yacyretá, iniciado em 2014, consistia na construção de um muro de concreto de $5 \mathrm{~m}$. alta e $300.000 \mathrm{~m}$. longo nas margens do rio Paraná (Posadas); gerar uma linha arquitetônica entre a população estabelecida no centro da cidade e a orla costeira onde está localizado o controle aduaneiro. Entendemos essa iniciativa como uma ação disciplinar, proveniente do estado, gerando um impacto direto nas relações fronteiriças e locais entre e nas cidades vizinhas de Posadas (Misiones, Argentina) e Encarnación (Paraguai). Então, nos perguntamos: que sentido esse muro faria para as sociedades que habitam essas espacialidades de fronteira? O olhar do regional / local e das margens nos permitirá observar, então, as diferentes formas de consolidação do poder e controle do Estado dentro dessas territorialidades.

Palavras-chave: Fronteira; Muro; Posadas (Missões); Encarnação (Paraguai).

\footnotetext{
${ }^{1}$ Becaria de investigación. Proyecto $16 \mathrm{H} 453$ denominado "Relaciones de poder: Misiones como problema historiográfico. Entre lo local y lo regional" bajo la dirección de la Mgter. Norma Oviedo. Secretaria de Investigación, Facultad de Humanidades y Ciencias Sociales, Universidad Nacional de Misiones.
} 
Abstract : The State builds and gives meaning to power in different ways, one of them is placing "on the margins" to certain territories that make up the national jurisdiction and planning the territorial planning within them. From this perspective, the controversial transit planning project in the border area executed by the Argentine National State, the Provincial State of Missions and the Yacyretá Binational Entity, initiated in 2014, consisted of the construction of a $5 \mathrm{~m}$ concrete wall. High and $300,000 \mathrm{~m}$. long on the banks of the Paraná River (Posadas); generating an architectural line between the population settled in the downtown area and the coastal edge where the customs control is located. We understand this initiative as a disciplinary action, coming from the state, generating a direct impact on border and local relations between and in the neighboring cities of Posadas (Misiones, Argentina) and Encarnación (Paraguay). So, we ask ourselves: What sense would that wall make for those societies that inhabit these border spatialities? The look from the regional / local and from the margins will allow us to observe, then the different forms of consolidation of power and control of the State within these territorialities.

Keywords: Border; Wall; Posadas (Missions); Encarnación (Paraguay).

\section{Introducción}

El siglo XXI se caracteriza por una falta de acuerdos totales concernientes al espacio físico, social y cultural de las denominadas regiones de frontera, en tal sentido, el controvertido proyecto de ordenamiento del tránsito en la zona fronteriza ejecutado por el Estado Nacional Argentino, el Estado Provincial de Misiones y la Entidad Binacional Yacyretá (EBY), iniciado en 2014, permite observar como las percepciones en torno al desarrollo urbanístico sufren cambios de manera continua y son objeto de negociación y remodelación constantes, producto de intereses contrapuestos entre los beneficiarios de estas acciones disciplinadoras - el estado y la represa - y los perjudicados - la población que habita y circula los espacios de frontera -.

Cada vez nos alejamos más del tratamiento estático de lo que aparentemente eran territorios establecidos de antemano, siguiendo con Douglass (1994) las fronteras no distinguen meramente sistemas sociales, culturales, económicos y políticos, sino que más bien determinan las zonas en donde tales sistemas se interpretan mutuamente de modo especial. Por tanto, la iniciativa ejecutada desde el estado, en este estudio de caso, es entendida como una "acción disciplinadora" (Bauman, 2004) que impacto directamente en el sistema de relaciones fronterizas y locales entre y en las ciudades vecinas de Posadas (Misiones, Argentina) y Encarnación (Paraguay) en relación al uso del espacio urbano.

$\mathrm{Al}$ respecto, y sin pretender ser exhaustivos, puesto que la investigación aquí presentada tiene un carácter de aproximación, nos preguntamos: ¿Qué sentido tendría ese muro para esas sociedades que habitan estas espacialidades fronterizas? Tomaremos, para emprender una posible respuesta, la visión de las instituciones estatales involucradas y la perspectiva de los medios de comunicación acerca del muro en cuestión; de hecho que esta última nos permite sumar las percepciones de los sujetos que cotidianamente transitan el lugar.

Priorizaremos una mirada desde lo regional y desde lo local (FERNÁNDEZ, 2007) puesto que la idea de la territorialidad en tanto espacialización de las prácticas sociales, configuradas desde la concepción, la vivencia y la experiencia de los que habitan el territorio; permiten en este caso problematizar "localmente" un hecho social que impacta en la región de frontera, además de acotar la problemática a un espacio - las relaciones fronterizas y locales entre y en las ciudades vecinas de Posadas (Misiones, Argentina) y Encarnación (Paraguay) y a un período determinado - 2014 a 2019 -. Los particularismos propios de esta ubicación temporo-espacial nos permitirán la comprensión del tiempo histórico, es decir de las 
duraciones, las variaciones, las rupturas y las velocidades con las que se sucedieron ciertos acontecimientos en esa espacialidad fronteriza; que presenta una movilidad pendular de sujetos que se ha ido incrementando y espacializando hasta constituirse en "una región argentino-paraguaya" según Cossi (2017).

Las distintas formas de consolidación del poder y del control del Estado al interior de dichas territorialidades, en tanto, prácticas y políticas de los sujetos con dinámicas propias de una vida fronteriza, moldeadas por unas políticas de regulación y disciplinamiento objetivadas en proyectos convenidos entre estado y represa, serán observadas poniendo el foco en esas redefiniciones que el bordelands o zona fronteriza transita en el devenir del 2014 al 2019 promoviendo cambios expresados concretamente en los modos de participación, intervención y transformación del espacio urbano; con fines de supervivencia política, social y económica o, dicho en términos de Ceniceros (2014), de mantención de la "plusvalía simbólica" de los sectores más pudientes de la sociedad.

\section{El borderlands un campo más donde es posible observar fenómenos culturales, sociales y políticos específicos}

Desde el comienzo de la investigación, siguiendo a Wolf (1987), nos permitimos pensar que el mundo de la humanidad se constituye como un total de procesos múltiples interconectados y que los empeños por descomponer en partes a esta totalidad hacen que luego no podamos rearmarla. Entonces, se produce un falseamiento y cosificación de la realidad, mediante la conversión/asignación de nombres a las "cosas" y, en tal sentido, aceptamos que la observación histórica se hace desde la teoría; siendo pertinente teorizar para analizar la complejidad que implica situarse, estar y ser situado en la región de frontera.

Así pues, la frontera en el borderlands de Posadas (Misiones - Argentina) y Encarnación (Paraguay) se caracteriza por ser al mismo tiempo 1) elástica y rígida, puesto que las transacciones se desenvuelven, en términos de Brites (2018), en planos "legales, ilegales o cuasi ilegales" y, en simultáneo, se suceden las correspondientes movilizaciones poblacionales que "sobrevivieron al muro"; mientras se implementa la puesta en marcha de la megaconstrucción del centro fronterizo y, por tanto, del polémico muro de hormigón de $5 \mathrm{~m}$. de alto y $300.000 \mathrm{~m}$. de largo en las orillas del río Paraná (Posadas). En ese marco se producen relatos y argumentaciones - 2) narrables - de los diferentes conflictos que precedieron a la construcción y fueron viralizados a través de los medios de comunicación en ambas ciudades en tanto ocurre un proceso de ocultamiento/silenciamiento - 3) inenarrables de la identidad transfronteriza de los sujetos que cotidianamente transitan entre, a través y más allá de los límites impuestos - 4) contenidas - por políticas, normas y acciones disciplinadoras - 5) incontenibles - porque son los sujetos quienes con sus prácticas y políticas de vida cotidianas se rebelan frente a las prácticas políticas de regulación y disciplinamiento venidas desde el estado.

Los procesos de apropiación del espacio habitado y los rasgos que asumen las prácticas cotidianas entre las ciudades vecinas de Posadas y Encarnación, han experimentado una serie de transformaciones urbanas que deben ser analizadas en consonancia con los procesos políticos y socio-económicos que se sucedieron tras la construcción del muro. Un caso particular, es el de los trabajadores fronterizos, puntualmente la situación de las paseras que con sus prácticas cotidianas vienen a poner en tensión esa dimensión real de la frontera, que siguiendo con Linares (2009), remite al ejercicio de la soberanía con respecto a los controles fronterizos, como controles migratorios, aduaneros, acuerdos internacionales, es decir, lo que sucede en el paso internacional. Al trasponer el límite estarán las paseras sometidas con más rigurosidad a los controles situados detrás del muro, que funciona como 
"amortiguador visual" del centro de frontera; dispuesto y concretizado en diferentes edificios de distinto tipo entre los que están las casillas de control, los scaners, los contenedores, los camiones y los automóviles.

Figura 1: Centro de Frontera Posadas (Misiones - Argentina) - Encarnación (Paraguay).
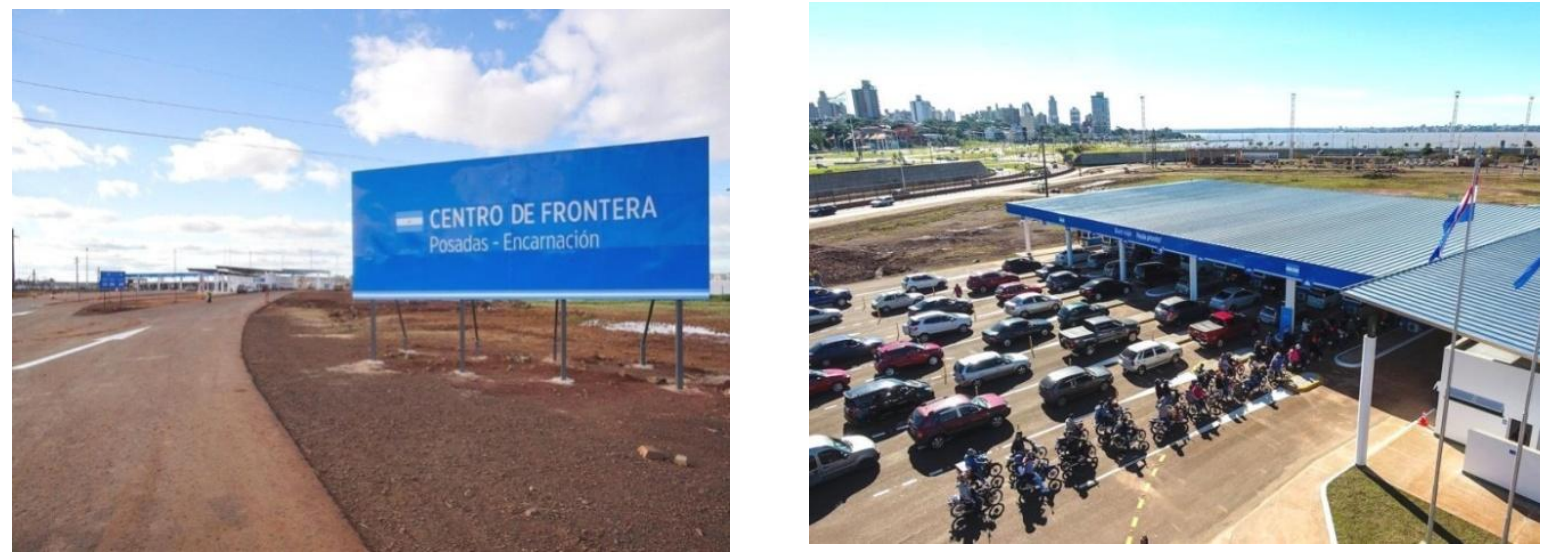

Fuente: Ministerio del Interior, Argentina - Centros de Frontera.

Las paseras en tanto personas provenientes de los estratos más carenciados, utilizan el régimen de tránsito vecinal fronterizo con el fin de subsistir, contrabandeando mínimas cantidades de objetos y productos para ser vendidos en la ciudad vecina, lo que se conoce vulgarmente como "comercio de pacotilla". Lejos de eliminar sus prácticas, producto de este contexto adverso y disciplinador, como señala Cossi (2017), su comercio informal transfronterizo se dinamizo y especializo "dando lugar a formas alternativas y combinadas que se crean y recrean con una enorme plasticidad". Inicialmente, las paseras cruzaban en lanchas con alimentos de sus propias chacras para comercializarlos en Posadas, este fenómeno está intrínsecamente relacionado con los orígenes de la ciudad, dado que en sus inicios fue un asentamiento urbano carente de una población rural cercana. En cuanto a las fronterizas a cargo de este oficio, siempre se sostuvo que las que iban y venían con mercaderías fueron mujeres con una economía de escala muy pequeña, esto último daría un giro abrupto con los años. Debido a que este contacto comercial desde Paraguay hacia la Argentina quedaría instalado como abastecimiento permanente, pero con algunos cambios que tenían por objetivo establecer aquello que se permitía cruzar y lo que estaba prohibido, es decir, la puesta en funcionamiento del estado como poder político institucionalizado, expresado en la posterior instalación del Mercado Modelo, denominado por los locales como "La placita".

La situación antes mencionada da cuenta que el muro claramente favorece a ciertos sectores de la sociedad, hablamos de los más acomodados de la capital misionera, con especial énfasis en las empresas de transportes, los comerciantes, y por supuesto a sus impulsores, el gobierno provincial y la Entidad Binacional Yacyretá - en detrimento de los trabajadores informales - y en ese sentido, se les otorgo una serie de beneficios. En principio a los comerciantes posadeños, más que beneficios concretos, les dio la posibilidad de especular respecto de la limitación de las compras a la ciudad vecina de Paraguay; esta regulación teóricamente sucedería tras la concreción del centro de frontera, escenario económico del todo propicio para la ciudad, sin embargo jamás sucedió de tal forma, inclusive fue tal el impacto negativo de esta megaconstrucción para este sector que termino siendo fuertemente repudiado por las cámaras de comercio de las ciudades vecinas involucradas (Posadas - Encarnación).

En relación a las empresas del lado argentino sucedió todo lo contrario, debido a las distancias extensas que debían recorrerse a pie para rodear el muro y, teniendo en cuenta que 
este paso fronterizo no permite la circulación peatonal, derivo en altísimas ganancias que cayeron en manos del transporte público - sea ómnibus o el $\operatorname{tren}^{2}$ - que se caracteriza por ser una empresa oligopólica en Posadas. Y finalmente, la Entidad Binacional Yacyretá y el Gobierno provincial que con este plan de ordenamiento del tránsito, se vieron beneficiados con una inversión binacional de US\$50 millones de dólares para la puesta en marcha, desarrollo y concreción del proyecto.

Figura 2: Mapa satélital. Padrón de ocupación del espacio fronterizo
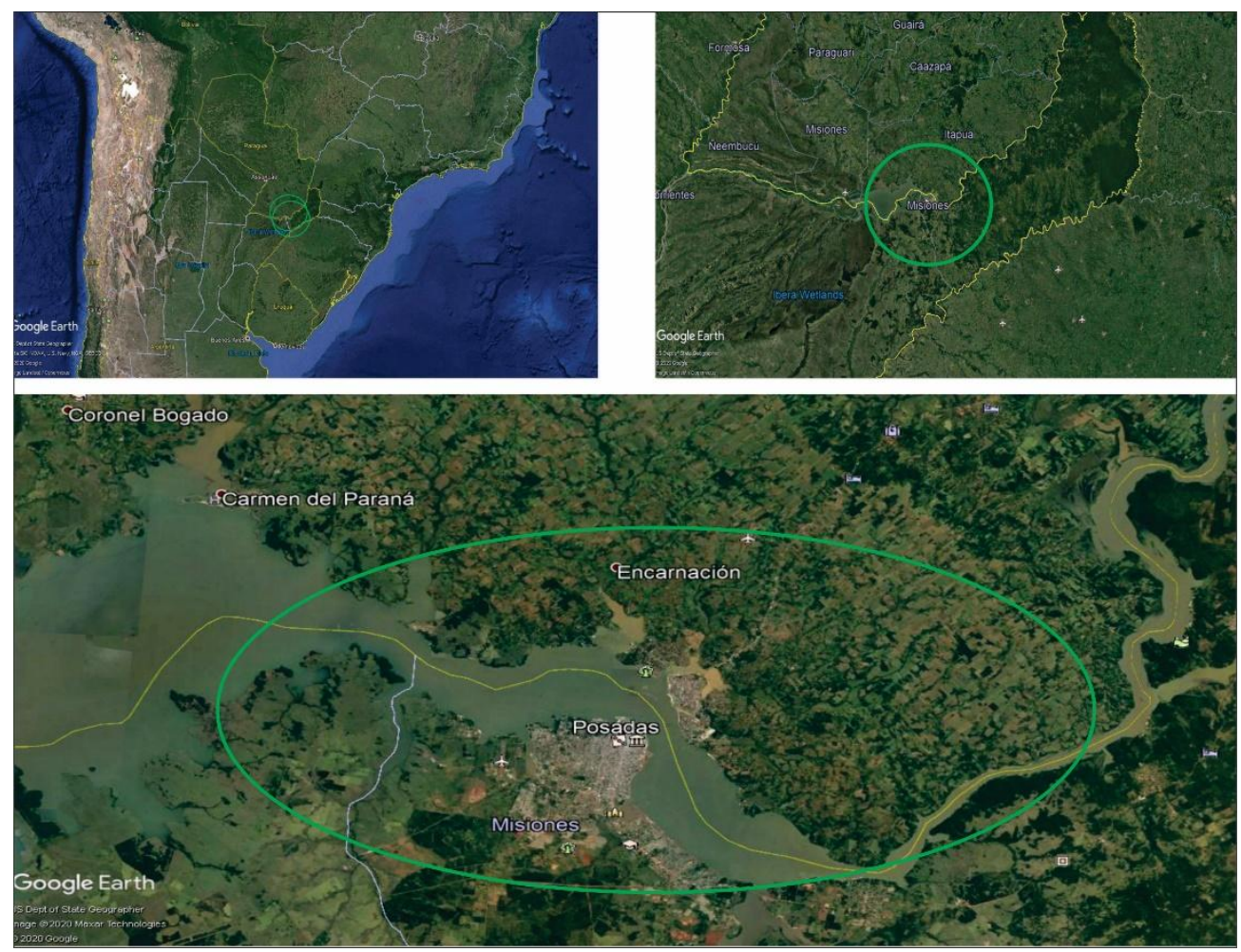

Fuente: Cossi (2017).

La frontera como tal y la consolidación de este centro fronterizo es compleja, dado que al establecerse en ella relaciones fronterizas, los conflictos de tipo económico y político son una constante que repercuten e impactan en los diferentes sectores de la sociedad; generando un campo de disputas en torno a sus intereses y a la necesidad de continuidad a sus actividades. En el caso de la EBY, los gobiernos de turno, las empresas de transporte y los grandes comerciantes, lo observamos expresamente en su decisión arbitraria de seguir adelante con la construcción del muro, dejando a un lado las voces del otro sector, es decir de aquellos trabajadores fronterizos y de la población vecinal en general - estudiantes, turistas, etc. - que utilizan este tránsito fronterizo cotidianamente y que se manifestaron en contra; através de los medios de comunicación de ambas ciudades.

Así, lo cotidiano en este borderland son las relaciones fronterizas que se engloban en tres dimensiones según la propuesta de Cossi (2017): a) la política que sería ese espacio delimitado, controlado y disputado en el que se ejercen relaciones de poder; $b$ ) la económica como la forma en que ese espacio genera los recursos para mantenerse tanto interna como

\footnotetext{
2 Según refiere Brites (2018: 14) "Hacia el año 2015, para contrarrestar el mayor tiempo de espera, se implementó el servicio de tren binacional como un servicio complementario al transporte urbano internacional, aumentando así la frecuencia de cruces".
} 
externamente; y, c) la cultural que refiere a lo que se considera como un producto de la apropiación/valoración simbólica de un grupo en relación a su espacio vivido. Como definición de dimensiones, esta perspectiva es por cierto muy relevante para comprender "algunas" manifestaciones de las ciudades en contexto de fronteras.

En concreto, la frontera no solo se constituye como una demarcación de límites, de diferencias, de separación de un espacio; sino que, también, como una interfase, un espacio de contacto, de permeabilidad y de relaciones sociales transfronterizas, donde el límite que puede ser a la vez temido, ignorado o transgredido, se transforma, a su vez, en el elemento aglutinador de estas relaciones.

\section{Fronteras borrosas y construcción discursiva de los medios de comunicación}

La dimensión simbólica de la frontera, en tanto espacio vivido, habitado y atravesado por un juego constante de subjetividades que se refieren, en este caso, a una conciencia cultural e histórica sobre sí mismos y sus intereses como fronterizos, en tanto pobladores de las ciudades de Encarnación (Paraguay) y Posadas (Misiones - Argentina), se ven signados, a decir de Cossi (2017), por "una alta movilidad, informalidad y adecuación constante a cada coyuntura"; esto nos lleva a señalar, de forma somera, lo expuesto por Brites $(2012,2014)$ en relación a los procesos de conurbación, cambios en su morfología, reorganización socioespacial y segregación urbana que están escenificando ambas ciudades como producto de las transformaciones en el desarrollo urbanístico ${ }^{3}$ impulsado por la represa, cambios que afectan directamente a las formas de habitar la frontera.

El entramado de medios de comunicación locales de estas ciudades nos remite a esa dimensión simbólica, expresada a través las demandas que las personas manifestaron ante esta megaconstrucción en la que, tal como Vezzetti (2003) planteó para otro contexto, los grupos pugnan por imponer sus representaciones al resto; en el terreno de la dimensión simbólica de las luchas políticas en las que compiten narraciones sobre el pasado que dicen mucho sobre las posiciones y las apuestas del presente. Un claro ejemplo a escala local, es el artículo periodístico de Gayetzky (2017) en el cual señalo que:

"Nuestro país, siempre a la vanguardia, hace ya unos años que tiene su muro. La vergüenza materializada, complicando el tránsito interno y el fronterizo. También afeando, y no es cosa menor, la vista maravillosa del río Paraná que tiene la ciudad de Posadas y el paisaje urbano que despliega la ciudad de Encarnación sobre la otra orilla. Lo peor es que se hizo perturbando las buenas relaciones con nuestros vecinos paraguayos. Con ellos nos unen lazos que trascienden la economía y se fundan en la familiaridad, en la amistad, pero también en la ayuda mutua que generosamente ofrecen ambas orillas y que en situaciones de desastre fueran tan beneficiosas."

A escala nacional, también nos encontramos con ciertos referentes políticos provenientes de sectores de la derecha, haciéndose eco de la situación y, por tanto, manifestándose en relación al proyecto de la EBY. Al respecto tomaremos los dichos del diputado nacional por UCR - Cambiemos, Luis Pastori (2015), quien expresaba a un medio local que:

\footnotetext{
${ }^{3}$ En relación a esta situación Cossi (2014) señalo que la Entidad Binacional Yacyretá a través de sus mega-obras de reordenamiento territorial produjeron incertidumbre y desesperación por parte de los ciudadanos de ambos márgenes, estos durante varias décadas, se vieron incitados a desarrollar distintas estrategias con el fin de sobreponerse.
} 
"La obra 'afea' la visibilidad de la Costanera. La EBY se cree dueña y señora de todo el ejido y hace lo que quiere sin consultar con nadie, cuestionó, al tiempo que añadió que presentará en la Cámara de Diputados de la Nación un pedido de informe sobre el tema."

Lo manifestado por la arquitecta argentina y el diputado, se puede relacionar con un escrito de Carbonari (2003) en el cual expone que el poder central deja intersticios donde los sujetos sostienen prácticas de resistencia y oposición a éste, acciones que pueden producir importantes transformaciones para su sociedad, esos intersticios en el borderland bajo análisis lo constituyen los medios de comunicación, que siguiendo con Orozco (1997), son fuente de referentes cotidianos representadores de la realidad y generadores de conocimiento, autoridad y legitimación política.

Ejemplo de resistencia a esta obra fue la petición de un ciudadano de la ciudad de Posadas que a través de la plataforma www.change.org, insto a los fronterizos de ambas ciudades para que la firmen, con el objetivo de lograr que los funcionarios detengan la construcción del muro, que como ya dijésemos se inició en el 2014 con vistas a concretarse pasados dos años, según informaron de fuentes oficiales de la EBY en su sitio web oficial ${ }^{5}$. Varios fueron los reclamos que aparecieron en el manifiesto que acompaña la petición, aquí retomaremos los que consideramos más relevantes, en tanto son una muestra de las distintas formas de consolidación del poder y del control del Estado como lo observamos en los dichos transcriptos a continuación:

"[1] Es realmente vergonzoso que las autoridades del Estado, sentados en un escritorio en una cómoda oficina en la Capital Federal, y sin conocer la realidad de las localidades fronterizas, hayan levantado un muro perimetral que bloquea el libre tránsito tanto de ciudadanos argentinos como extranjeros, especialmente paraguayos.

[2] Mientras autoridades del MERCOSUR intentan profundizar las relaciones de los países que lo integran, es vergonzoso que la Entidad Binacional Yacyretá (EBY) haya construido semejante obra de hormigón, que impide el paso de estudiantes, turistas, y castiga al 'comercio de pacotilla'. Este hábito que forma parte de la cultura regional, permitiendo la supervivencia de los más humildes en ambas márgenes del Paraná.”

Esta convocatoria finalizo con un total de 8.206 firmas, cifra que da cuenta de los lazos de amistad y de cooperación mutua entre y en las ciudades afectadas ya que, tal como lo señalo Brites (2018), ambas nacieron de un mismo proceso sociohistórico y, desde sus orígenes, estuvieron íntimamente ligadas a la frontera e insertas en la región de frontera (OVIEDO, 2014); compartiendo fluidas interacciones y estrechos vínculos socioeconómicos y culturales". De hecho, desde el lado paraguayo, las voces de los ciudadanos también se hicieron eco, en los diferentes medios locales, tanto escritos como testimonios divulgados a través de los periódicos, las redes sociales y los canales de televisión. Aquí citamos un diario online, dado que pone en cuestionamiento otro eje en relación a la polémica, referida a la distribución de fondos económicos por parte de la represa binacional para estos proyectos, señalando la aparente disparidad entre las ciudades afectadas ya que:

\footnotetext{
${ }^{4}$ Se consultó la nota: La EBY defiende el muro de frontera: "Nos pedían que hagamos un alambrado". Misiones Online, Posadas, 2015.

${ }^{5}$ Sitio web oficial de la Entidad Binacional Yacyretá: «https://www.eby.org.ar/».

${ }^{6}$ Se consultó: Petición de firmas "Detengan la construcción del muro que divide Argentina y Paraguay", Plataforma virtual Change.org, 2015.
} 
"Actualmente los usuarios deben realizar un largo recorrido de más de tres kilómetros desde la cabecera del puente San Roque hasta cercanías del puente sobre el arroyo Zaimán (...) distancia que se debe recorrer para entrar o salir del centro de Posadas [además] Lo cuestionable de este hecho es que mientras invierten millonarios fondos en el lado argentino, en territorio paraguayo solo colocan unas cuantas 'migajas'. En contraste con la portentosa obra de Posadas la EBY del lado paraguayo comenzó a instalar baldosas y luces en la antigua 'zona baja' abandonada hace años."7

Como se observa, el lado paraguayo distingue, por un lado, las diferencias con respecto a los fondos destinados para cada lado respectivamente $\mathrm{y}$, por otro lado, el largo recorrido que se debe realizar para entrar y salir del centro fronterizo. Recordemos que los costos de la obra fueron disminuyendo a medida que la obra continuaba, producto de los cambios en la dirección ejecutiva al interior de la EBY. Sin embargo, no podemos dejar de mencionar que, pese a este reclamo proveniente de los medios locales de Encarnación, esta ciudad se vio afectado por fuertes inversiones por parte de la represa; lo que derivó en amplias transformaciones socio-espaciales que, según el punto de vista de Brites (2018), permite su desarrollo como "conurbación en crecimiento". Esto también sucede en Posadas, en tanto ciudad fronteriza o "ciudad gemela", afectada también por las decisiones tomadas de común acuerdo entre los estados.

Tabla 1: Detalles de las inversiones

\begin{tabular}{l|l}
\hline $\begin{array}{l}\text { Primer proyecto con doble túnel } \\
\text { Arq. Oscar Thomas }\end{array}$ & $\$ 213.560 .000$ \\
\hline $\begin{array}{l}\text { Segundo proyecto con acceso rápido } \\
\text { Lic. Martín Goerling } \\
\text { Detalles }\end{array}$ & $\begin{array}{l}\$ 7.000 .000 \\
750 \mathrm{~m} \text {. de longitud total del muro existente y } 5 \mathrm{~m} . \\
\text { de altura promedio. }\end{array}$ \\
Volumen & $\begin{array}{l}\text { Hormigón en el muro existente } 3.280 \mathrm{~m}^{3} \text { y longitud } \\
\text { a demoler } 60 \mathrm{~m} . \text { que implica } \\
30.000 \mathrm{~m}^{3} .\end{array}$ \\
\hline
\end{tabular}

Fuente: Prensa local, El Territorio ${ }^{8}$ (2017). Elaboración propia.

La similitud que opera en las percepciones de los habitantes de frontera respecto del proyecto binacional del centro fronterizo, puntualmente sobre el muro y la forma en que esta construcción afecta a las personas, viene dada por las prácticas colectivas e individuales de los propios agentes sociales fronterizos, principales defensoras de esta postura integracionista son Oviedo y Arellano (2017) quienes consideran que las relaciones y prácticas sociales definen a la frontera como un espacio de integración y encuentro, basado en las vivencias y experiencias comunes de los sujetos que lo habitan.

Numerosos son los sentidos que adquieren, entonces, los muros en las sociedades contemporáneas, comenzando por el significado económico que en síntesis asignan el estado y los comerciantes posadeños al funcionamiento del centro fronterizo, como un freno al contrabando ${ }^{9}$. Esto sucedería a través de un control más estricto de las formas de movilidades

\footnotetext{
${ }^{7}$ Se consultó la nota: "Mentiras y verdades sobre el polémico muro". Por nuestra redacción regional, ABC color, Paraguay, Agosto 2015.

${ }^{8}$ Se consultó: "Comenzarán a demoler parte del muro para construir nuevos accesos", El territorio, Diario online, julio 2017.

${ }^{9}$ Entendemos el contrabando como un fenómeno que se ha generalizado en nuestra cultura, en nuestro modo de vida, siendo legitimado en los mecanismos de intercambio comercial que sustentan la cultura nacional. Y allí es donde se despunta el grado de dificultad para enfrentar el conflicto ya que este permanece inserto en redes de
} 
que se dan de una ciudad a la otra, impulsando primeramente - y dado que el mismo muro de cemento coarta otras posibilidades de acceso al casco céntrico de la ciudad -, por el cruce estrictamente en automóvil, taxis, colectivos urbanos o en tren. Además, la especulación que se desarrolló en torno a la disminución de compras "del otro lado", por parte de los argentinos, fue un motor para el apoyo de los pequeños y grandes comerciantes al proyecto de la EBY.

Sin embargo, como ya adelantáramos, las condiciones laborales de trabajo informal y el tráfico "legal, ilegal y cuasi ilegal" (BRITES, 2018) como partes constitutivas de esta zona fronteriza, no hicieron más que incrementarse y especializarse a punto tal que Cossi (2017) plantea que los fronterizos tienen "una vida inscripta en la trasnacionalidad"; que viene dada por sus actividades económicas informales - en el caso de las paseras - o también producto de relaciones sociales multipropósito (vecinales, laborales, comerciales y hasta familiares) desarrolladas cotidianamente a uno y otro lado del límite.

El sentido político - jurídico permanece intrínsecamente relacionado con el económico y, se expresa específicamente en como este centro fronterizo tratara la situación de esa "vida trasnacional" que mencionamos arriba, es decir cómo va a funcionar esta maquinaria de disciplinamiento instituida por el estado a la hora de administrar movilidades y permanencias entre y en las ciudades vecinas; en resumidas cuentas "qué, quiénes, en qué condiciones, con qué motivos, y por cuanto tiempo pueden atravesar la frontera" (COSSI, 2017), lo cual se realizaría en conformidad con los sistemas legales nacionales que, a su vez, están relacionados con entidades mayores como ser los tratados, bloques regionales, etc.

Respecto del sentido socio - cultural, según las fuentes impulsoras del proyecto entre ellas el ex director de la EBY, arquitecto Oscar Thomas - el muro serviría como protector visual en tanto la propuesta - que se llevaría a cabo posteriormente - era realizar pinturas, grafitis, etc. sobre el muro; a cargo de artistas - muralistas convocados desde distintos puntos de la Argentina y de Paraguay. Además, estaba prevista la construcción de espacios verdes alrededor, parques recreativos y saludables que funcionarían como "amortiguadores" del impacto visual negativo y como espacios de socialización y esparcimiento para la sociedad.

La propuesta artística del mural recién se puso en marcha a fines de octubre de 2019, bajo el proyecto titulado "Yacyretá nos une", esto permitió a que la empresa le diera un sentido socio - cultural de integración a este centro de frontera para, así, disminuir los cuestionamientos y críticas venidas desde diferentes sectores de la sociedad, tanto argentina como paraguaya, en relación al muro; como construcción que obstaculiza la visión al río Paraná y los lazos de cooperación y fraternidad con el país vecino; además de obstruir el paso peatonal hacia la zona céntrica de Posadas. Al respecto el actual director de la EBY, Licenciado Martín Goerling puntualizo que:

"Fue un desafío sin precedentes, una obra única que brindó la posibilidad de participación a artistas muralistas nacionales e internacionales, hermanando la frontera binacional, en una muestra de afecto, unión, paz y fraternidad entre Argentina y Paraguay, con el fin de mostrar al mundo nuestras culturas, arte y belleza natural."

La intervención artística del muro de $1.400 \mathrm{~m} 2$ de largo, emplazado alrededor del centro de frontera, según las fuentes oficiales de la EBY se constituye en "un relato de los lazos culturales e históricos de Argentina y Paraguay"10, fue realizada por 50 prestigiosos

corrupción, que multiplican el perjuicio del Estado, que no recibe la justa tributación por esos intercambios realizados al margen de la ley (CHIRIBOGA ZAMBRANO, 2015: 2).

${ }^{10}$ Se consultó: "El mural más grande del mundo", Entidad Binacional Yacyretá, 2019. 
artistas en conjunto con el Movimiento Internacional de Muralistas Ítalo Grassi, durante los días 5 al 20 de octubre de 2019. El proceso de creación artístico fue registrado en formato documental y posteriormente divulgado por diferentes plataformas: YouTube, sitio oficial de la EBY, canales de televisión local, entre otros.

Figura 3: Propuesta de espacios verdes y parques recreativos
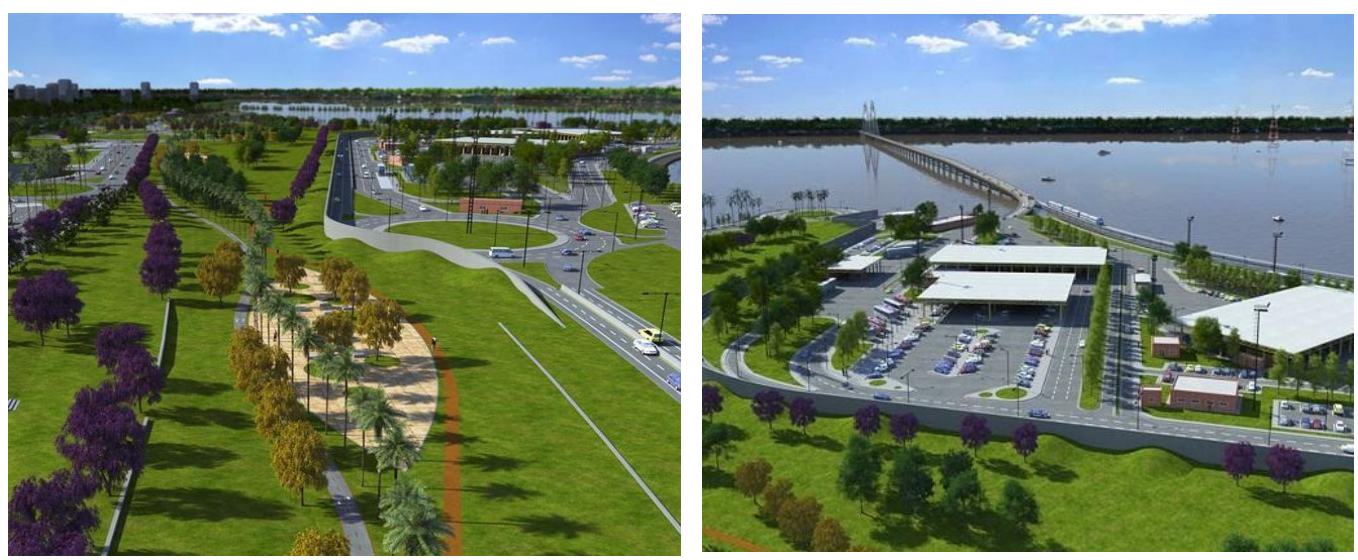

Fuente: Prensa local, Misiones Online (2015).

El financiamiento de los costos de la obra artística $^{11}$, el registro audiovisual denominado "El mural más grande del mundo"12, la estadía de los artistas, el transporte de los estudiantes de las escuelas, de ambos lados de la frontera que intervinieron, el acto de cierre con reconocidos artistas locales y demás cuestiones afines, estuvo a cargo del estado provincial y, en mayor medida, por la EBY. De modo que los sentidos que los artistas le otorgaron a la obra estuvieron condicionados por un esquema de autorización institucional, donde se puso en juego el uso legítimo de las paredes del muro, inscribiendo la práctica artística en un marco de legalidad.

Ceniceros (2014) señala que "participan de esta escena no solo los realizadores sino además los propietarios jurídicos de los muros, y los sectores gubernamental, artístico y comercial, en una suerte de revalorización de la práctica" y, si bien centro su estudio en Tijuana y sobre todo en el street art, esta aseveración nos permite deslindar para nuestro estudio de caso, no solo la práctica del artista perse sino también la revalorización del polémico muro ahora transformado en un símbolo de unión; quedando la represa de Yacyretá como la impulsora de este espacio de participación binacional, objetivos que supo sintetizar en el documental el director ejecutivo de la represa Goerling afirmando que:

"El muro que construyó Yacyretá en el 2014 - 2015 fue muy polémico en nuestra ciudad, en nuestra sociedad ¿no? Incluso trascendió las fronteras de Misiones y hubo mucho revuelo con ese muro y hubo muchas quejas también del país hermano de Paraguay. Y eso generó mucha polémica, porque los muros como símbolos separan en vez de unir, totalmente contrario a lo que es Yacyretá ¿no?

\footnotetext{
${ }^{11}$ Según la coordinadora Valeria Garibotti se usaron unos 1.200 litros de pintura, 800 lápices negros, los andamios, etc.

12 Documental "El mural más grande del mundo", octubre 2019, se encuentra disponible en: « https://www.youtube.com/watch?v=MyFPY6nmrR8».
} 
Yacyretá es una empresa binacional, que la mitad de Argentina y la mitad es paraguaya."13

Como mencionamos con anterioridad, la autorización de los propietarios del muro para su intervención se realizó a través de una convocatoria a artistas de Misiones, Formosa, Jujuy, La Pampa, Buenos Aires, Mendoza, Córdoba y San Luis y también de Perú, Bolivia y Paraguay e, inclusive a las instituciones educativas y vecinos que se acercaron a colaborar. La coordinación de este colectivo de personas, estuvo a cargo de la artista plástica y referente del Movimiento Internacional de Muralista por Misiones Valeria Garibotti, quien decidió dividirlos en equipos artísticos y distribuirlos en un total de cinco sectores, cada uno con su respectivo coordinador/a, lo que destaca el carácter de creación colectiva o como dijese la muralista Garibotti: "El muro se hace de soporte para todo esto que se está creando en conjunto" en contraposición a la tradicional soledad del artista.

Figura 4: Equipos artísticos y sectores del mural

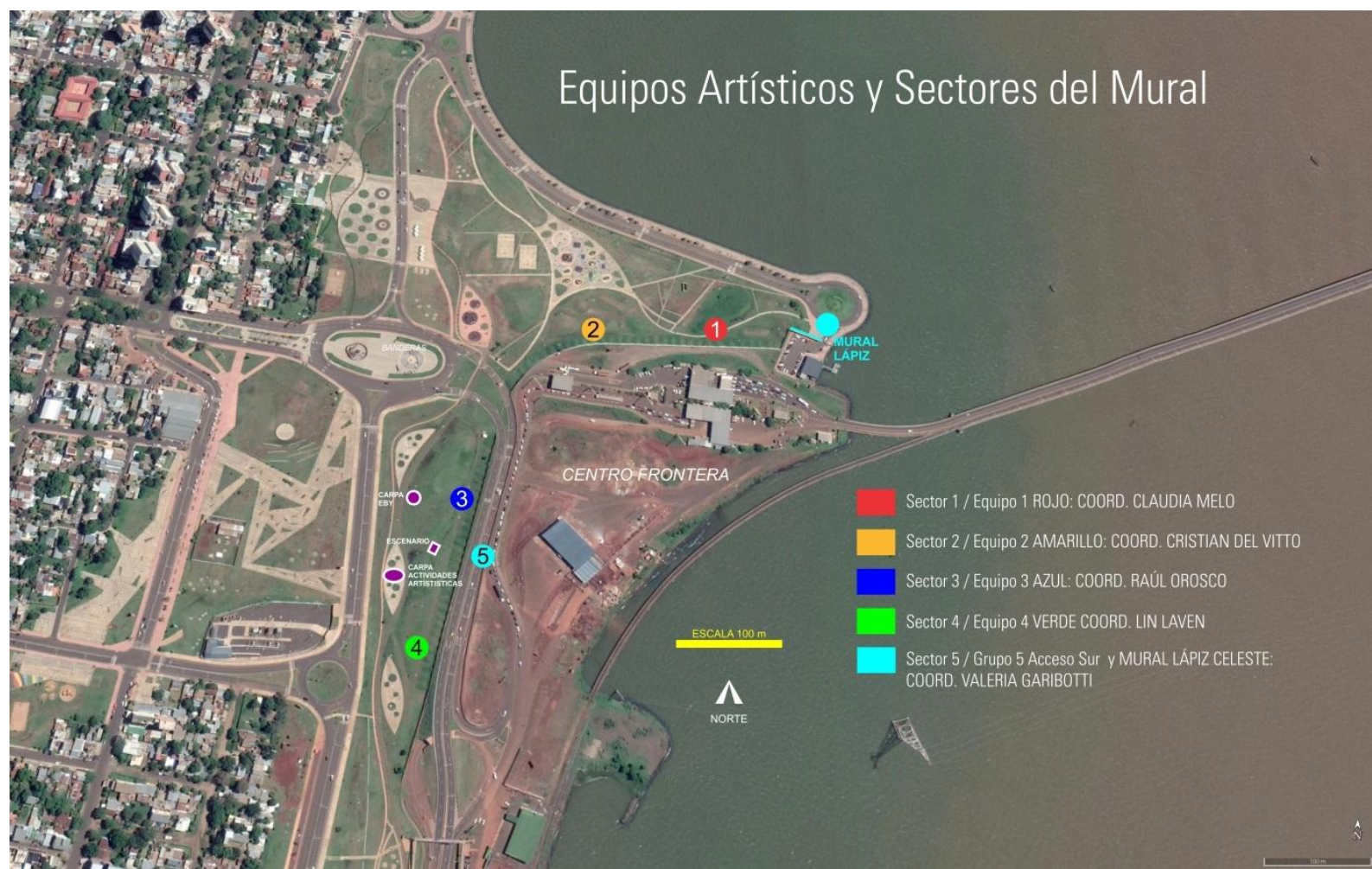

Fuente: Entidad Binacional Yacyretá (2019).

El muralismo como expresión artística modificadora de la estética del espacio urbano y a la vez "como símbolo, como estrategia de apropiación, como emocionalidad comunicativa patrimonial" (CENICEROS, 2014), en este caso se ciñó a ciertas temáticas regionales y, según lo expresado por el muralista de Perú Víctor Manuel Yava Vallejos, el hilo conductor fue "la historia y la hermandad de los pueblos", indicativo de la intencionalidad de los funcionarios y de los nuevos usos que se pretendía dar a ese espacio una vez territorializada la identidad - a través del mural - y que desde el estado provincial se pretende dar a Misiones ${ }^{14}$.

\footnotetext{
13 Ídem.

14 Para ampliar sobre "el misionerismo" impulsado desde los funcionarios estatales ver: Jaume, Fernando (comp.). Luchas por la hegemonía. Historias y etnografía en la Provincia de Misiones, Argentina. Posadas: EDUNAM - - Editorial Universitaria de la Universidad Nacional de Misiones, 2017. Con especial énfasis en el
} 
Sin embargo, aquí no pretendemos un abordaje semiótico de las representaciones que se dejaron plasmadas, sino más bien puntualizar en el sentido socio - cultural otorgado, nos encontramos entonces con ciertos personajes históricos y contemporáneos, objetos, animales costumbres, paisajes y acontecimientos que sobresalen, a saber: la mujer guaraní desde los diferentes roles que ocupa en la sociedad ${ }^{15}$ y la cultura mbya guaraní, los jesuitas, el reconocido músico local Chango Spasiuk, los yaguaretés, la selva misionera, la flor nacional de Paraguay "la pasionaria", el mate, la yerba, los tareferos, las banderas de Argentina, Misiones, Paraguay y la whipala, las cataratas de Iguazú, la cruz de Santa Ana, el héroe Andrés Guacurarí y Artigas, los trabajadores rurales, el avance de la industria, la EBY y sus aportes a las ciudades, entre otras; van reforzando, por vía del pasado entrelazado al presente, el poder y la dominación de un relato histórico como resultado de un proceso que se fue consolidando paulatinamente y que ahora es sintetizado por la represa bajo el proyecto "Yacyretá nos une".

Figura 5: El mural
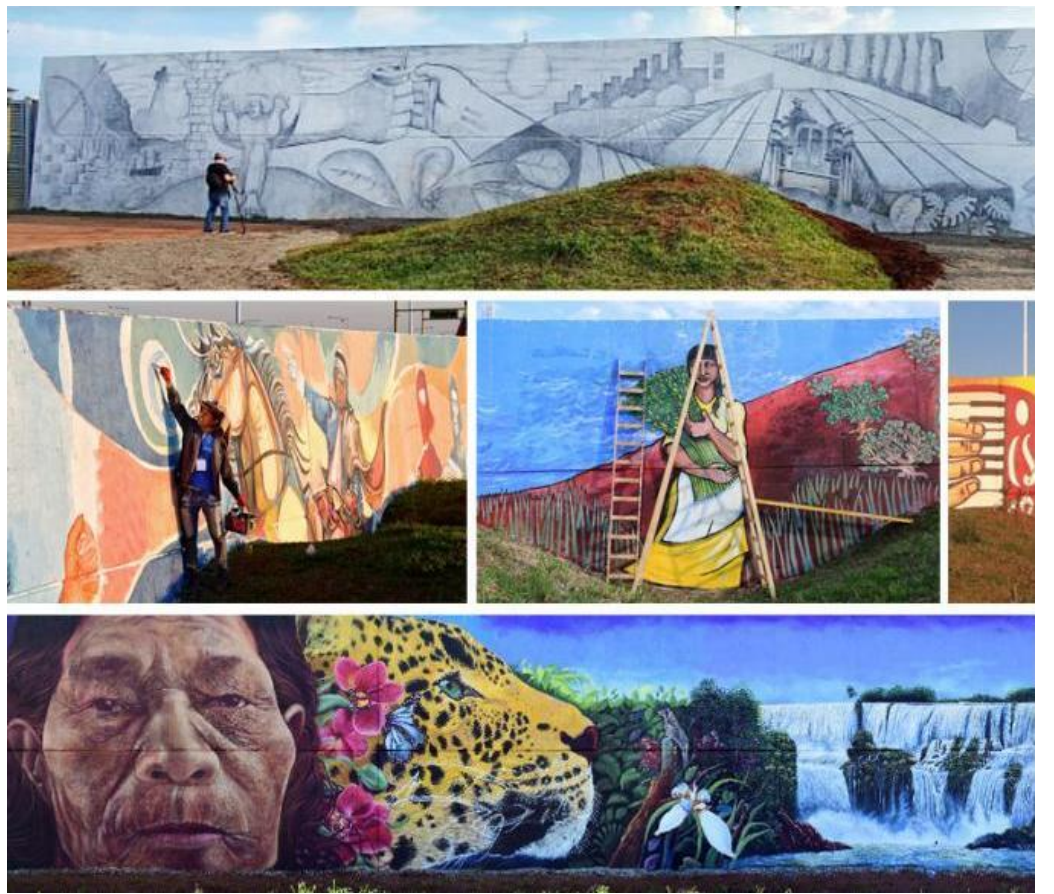

Fuente: Entidad Binacional Yacyretá (2019).

Merece ser señalado entonces el triple proceso por el que la ciudad de Posadas, está siendo atravesada: a) delimitación de un campo de poder que, como sostiene Bourdieu citado por Ceniceros 2014 pp. 20 - 21 y Jaume 2017 p. 2 - refiere a esa estructura simbólica relativamente autónoma que posee una lógica particular y opera como un sistema de relaciones sociales y a cuyos participantes les corresponde un habitus específico bajo el cual han de guiarse las acciones, pensamientos y percepciones; en este caso son los actores políticos, funcionarios estatales y la EBY que convinieron en el desarrollo de esta actividad, con el fin de asegurar su supervivencia socio - política, dada las polémicas generadas como producto de la megaconstrucción; $b$ ) recuperación/apropiación de una construcción discursiva anclada en una narrativa oficial "misionerista" que se impone producto de un elaborado

Capítulo 2 “Estamos inmersos en una batalla cultural! Hegemonía y usos del pasado en el presente misionero" de los autores Jaume Fernando y Ebenau Laura.

${ }^{15}$ Según la muralista María Luisa Sosa, encargada de esta sección menciono en el documental que: "la temática que elegí fue la mujer. La mujer y su rol en la sociedad, la mujer y la familia, la mujer y el trabajo, la mujer que necesita que se reconozcan sus derechos. Hemos tratado de visibilizar a través de la mujer guaraní". 
trabajo de (re)invención, a través de la, $c$ ) sistematización/apropiación de un relato que se refleja en la variada puesta en escena que se realizó antes, durante y después de la finalización de la obra artística.

Un claro ejemplo en ese proceso de apropiación del relato y aparente necesidad de instalar esa (re)invención de la narrativa oficial - entiéndase que los impulsores de este proyecto no inventan una tradición sino que resignifican una tradición existente arraigada en la comunidad local - por todas las vías, fue la solicitud al Guinnes World Records de reconocimiento mundial de esta obra y la posterior certificación como el mural más largo del mundo hecho a lápiz. Varios fueron los requisitos: a) debe ser superior al actual récord de la lista $85,2 \mathrm{~m}^{2} ; b$ ) tener una protección para que la obra perdure en el tiempo; $c$ ) que fuera correspondiente a una obra preestablecida y pre - autorizada de parte de Guinnes World Records. Luego de que se realizara por parte de Guinness World Records - el 19 de octubre de 2019 - la verificación oficial del mural hecho a lápiz, en conjunto con un agrimensor experto $^{16}$ en pesas y medidas que constato el total de $149,59 \mathrm{~m}^{2}$ de largo del mural pintado a lápiz, Posadas adquirió el título de récord mundial.

Figura 6: Certificación de Guinnes World Records
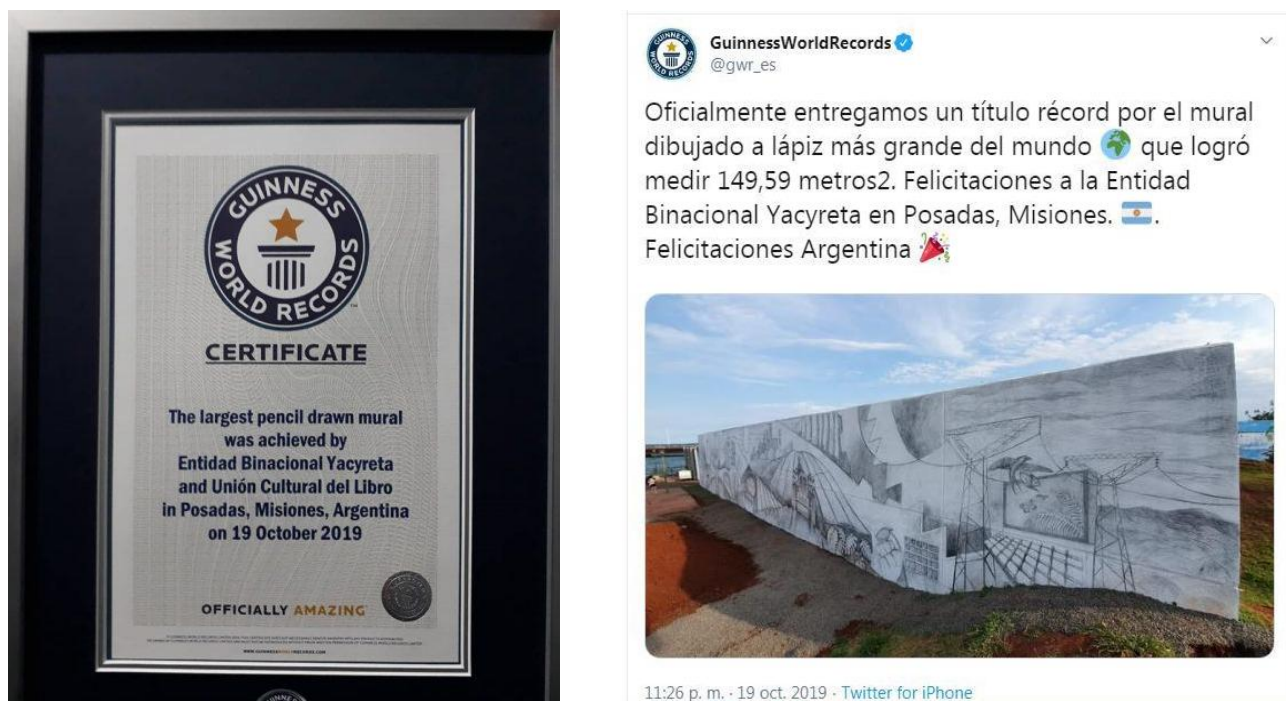

11:26 p. m. 19 oct. $2019 \cdot$. Twitter for iPhone

Fuente: Prensa local, Noticias del $6^{17}$ (2019) y Cuenta Oficial de Twitter de Guinnes World Records ${ }^{18}$.

Es en este sentido que hay que visibilizar el nivel de construcción y de operación sobre el sentido común que ese relato impone, puesto que establece ciertas continuidades con el pasado histórico y el presente, ahora sintetizados en la represa Yacyretá como la entidad que une a las ciudades de frontera, y es la ciudad de Posadas, a través de su muro en tanto "espacio practicado" que territorializa esa identidad y en cuanto espacio con lugares apropiados por los usuarios con titularidad legal y ahora con titularidad histórica-culturalpolítica sobre el pasado que recrean la identificación simbólica individual y grupal de los

\footnotetext{
${ }^{16}$ Según una nota publicada en el sitio web del Guinnes World Records, fue necesario llevar a cabo "una técnica de medición muy precisa, puesto que al no ser una pared uniforme y tener varias curvas se requirió de un experto con alto conocimiento para calcular la medida exacta del mural".

${ }^{17}$ Se consultó la nota: "Mural de Posadas recibió el título récord por la superficie dibujada a lápiz más grande del mundo", Noticias del 6, 2019.

18 Se consultó el sitio oficial en Twitter Guinness World Records «@gwr_es», disponible en: «https://twitter.com/gwr_es/status/1185744139167686661?ref_src=twsrc\%5Etfw\%7Ctwcamp\%5Etweetembed \%7Ctwterm\%5E1185744139167686661\&ref_url=https\%3A\%2F\%2Fwww.noticiasdel6.com\%2Fmural-deposadas-recibio-el-titulo-record-por-el-mural-dibujado-a-lapiz-mas-grande-del-mundo\%2F [enero 2020]».
} 
fronterizos, a través de procesos de acción-interacción-transformación de ese espacio de frontera vivido y entonces ¿Quién podría discutirles a los funcionarios si construyen desde esa prédica de la unión basada en los lazos de mutua cooperación y dependencia entre ambas ciudades? De hecho, tras esta certificación del Guinnes World Records, las repercusiones en torno al repudiado muro dieron un viraje, donde antes había cuestionamientos sobre la decisión del proyecto, ahora nos encontramos con felicitaciones a los impulsores del centro de frontera. Teniendo en cuenta que las relaciones humanas se forjan en la comunicación en tanto componente ineludible de las actividades sociales, León (2018) propone que la dinámica social presupone entonces un proceso comunicacional con configuraciones reticulares flexibles y que con la llegada de internet profundiza su alcance, velocidad y complejidad.

Figura 7: Redes sociales.

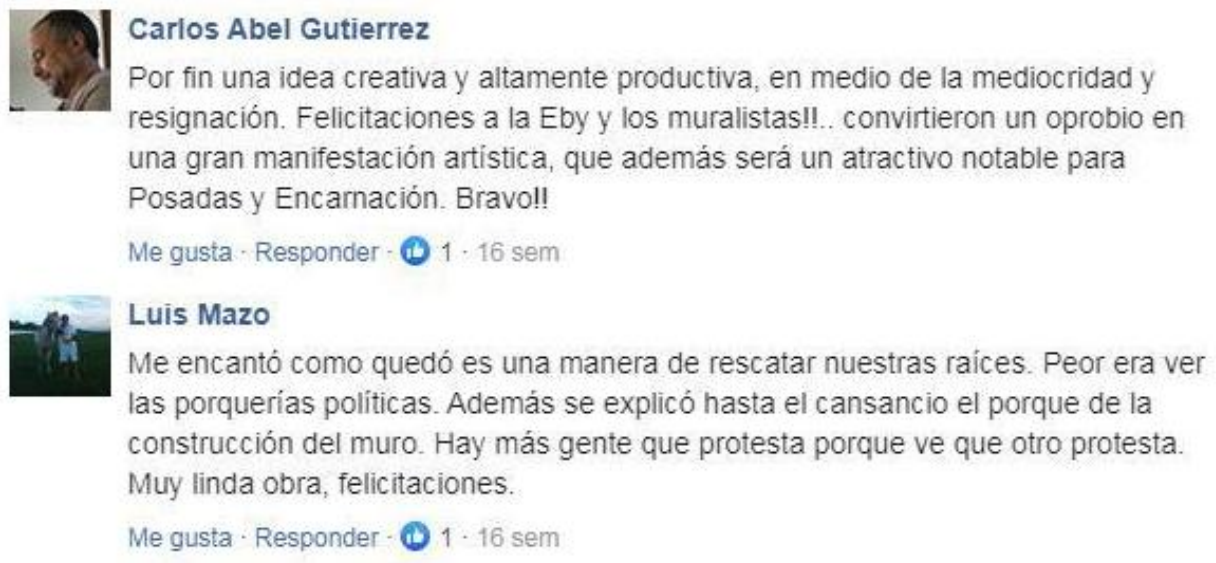

Fuente: Prensa local, El Territorio ${ }^{19}$ (2019).

En tal sentido, es que destacamos que en las redes sociales se pudo observar, tras la (re)invención del muro, algunos ejemplos en los comentarios al final de las notas online respecto del mural (Figura 7) o lo expresado por el reconocido intérprete local Chango Spasiuk manifestando "Me pareció una buena idea de la gente de Yacyretá de convocar a estos artistas y que hagan una intervención en esa pared, llamar un montón de artistas y que estos artistas dejen una impronta sobre esas paredes, de alguna manera es resignificar ese espacio" 20 , además los muralistas y la artista a cargo de la coordinación de los equipos de trabajo Valeria Garibotti expresaron: "Se está transformando de un frío muro en algo artístico", "Cambio totalmente el paisaje urbano, ya no vemos más ese muro gris o blanco, feo, duro. Sino que ahora vemos arte" ${ }^{21}$. De modo que en esta disputa de sentidos y percepciones cambiantes en torno al centro fronterizo con su polémico muro, da cuenta de cómo el estado opera para respaldar, promover y legitimar una nueva percepción en torno a sus prácticas - generadoras de crisis constantes en esos márgenes - y así van redefiniendo, producto de las necesidades imperantes, sus proyectos para mantener su "plusvalía simbólica" (CENICEROS, 2014) en el espacio local y poder entonces seguir cotizándose más y mejor; siendo ahora reconocidos por los fronterizos dentro de un campo binacional a partir de un capital global acumulado.

\footnotetext{
19 Se consultó la nota: "Posadas: entregaron el título récord por el mural dibujado a lápiz más grande del mundo", El Territorio, 2019. (https://www.elterritorio.com.ar/posadas-entregaron-el-titulo-record-por-el-muraldibujado-a-lapiz-mas-grande-del-mundo-47244-et [febrero 2020]).

20 Documental "El mural más grande del mundo", octubre 2019, se encuentra disponible en: « https://www.youtube.com/watch?v=MyFPY6nmrR8».

21 Ídem.
} 
Esto nos lleva a reconocer finalmente a las ciudades fronterizas como espacios en constante redefinición y transformación producto de las acciones, en este caso de los funcionarios del estado y de la represa que en pos de una (re)invención de las tradiciones a partir de la intervención en los espacios públicos, autorizados por ellos mismos, en tanto intervención realizada bajo un esquema legal; así las instituciones y el estado le atribuyen a su participación un propósito y significado que hacen de ese muro, devenido en obra artística, la expresión de una territorialización de la identidad misionerista y como la representación de unidad binacional de modo que el muro opera como refuerzo de un proyecto político de factura reciente consolidando su poder a través de acciones disciplinadoras y modificadoras del paisaje urbano.

\section{Consideraciones finales}

El proyecto de consolidación del centro de frontera situado en la ciudad de Posadas (Misiones, Argentina) que linda con Encarnación (Itapúa, Paraguay), en tanto planificación territorial que impacta y modifica la experiencia de los habitantes de la región de frontera, se constituyó en objeto de estudio de este trabajo; resultando en una aproximación respecto de las tensiones, que durante el desarrollo de las obras y la concreción del muro, se observaron en los medios de comunicación locales en ambas márgenes del río Paraná.

Así, el hilo conductor fue la pregunta respecto de los sentidos que tienen los muros para las sociedades que habitan estas espacialidades fronterizas, situación que, metodológicamente, implico la utilización de diferentes tipos de fuentes, que fueron claves para el abordaje de la problemática, la investigación; a las que, mayoritariamente, se accedieron vía online en los sitios oficiales y plataformas virtuales de las instituciones implicadas, además de los multivariados artículos periodísticos de los medios de comunicación tanto paraguayos como argentinos. También, analizamos el documental realizado por la EBY, que relata todo el proceso que implico llevar a cabo el proyecto "Yacyretá nos une" y que tenía como principal objetivo inscribir un imaginario sobre la resignificación del muro; fundamentando la intervención artística, realizada por muralistas convocados desde diferentes lugares de Latinoamérica, a fin de aplacar las críticas negativas generadas en torno a la construcción del muro.

A nivel general, nos situamos en los estudios regionales, puesto que nos circunscribimos a un espacio acotado, problematizando localmente las relaciones fronterizas y locales entre y en las ciudades vecinas o "gemelas" en un período igualmente delimitado (2014 a 2019). Para analizar los particularismos propios de nuestro objeto, fuimos deslindando teóricamente, concepciones tales como "plusvalía simbólica", "campo de poder", "frontera", "bordelands", "misionerismo" y "(re)invención", entre otras, venidas desde variados campos de estudios, puesto que fue necesario ir entre, a través y más allá de la disciplina histórica, para adentrarnos en la comprensión de las duraciones, variaciones, rupturas y velocidades con las que se sucedieron los acontecimientos; sobre todo el viraje en cuanto a los sentidos que, en principio, se le atribuyeron a la mega construcción. Pudimos observar dos cuestiones: $a$ ) desde una abstracción analítica podemos distinguir tres sentidos: socio - cultural, político - jurídico y económico; y, b) esos sentidos están representados por los dos sectores sociales que se disputan, entre sí, las formas de apropiación y uso del espacio a través de los medios de comunicación locales en ambos márgenes.

Sin embargo, producto del triple proceso por el cual la ciudad de Posadas se vio atravesada, una vez que los funcionarios de la represa en conveniencia con el estado provincial desplegaron su accionar, delimitaron un campo de poder y de disputas sobre la recuperación/apropiación de un espacio concreto mediante una construcción discursiva; 
anclada en una narrativa oficial "misionerista" sistematizando un relato expresado a través de la escenificación artística - que venía a instalar una continuidad entre el pasado jesuítico guaraní y el presente misionero -hilvanando la mutua cooperación y dependencia entre las ciudades afectadas por el centro de frontera. Así los usos y apropiación del espacio dados en un marco de legalidad, venía a promover y legitimar una nueva percepción en torno a sus/las prácticas para redefinir y justificar, a partir de las tradiciones regionales, los alcances de un proyecto político conjunto.

Devenido en su y nuestro proyecto, como lo dejamos planteado en el apartado dos, entonces no habría quién o quiénes se atrevieran a poner en tensión las prácticas de la EBY, teniendo en cuenta que su anclaje tiene basamento en ciertos procesos socio - históricos que marcaron a ambas ciudades, desde sus orígenes, a tal punto que, contemporáneamente, se las denomine "ciudades gemelas". De hecho que esta (re)invención y (re)significación del espacio fronterizo, en tanto territorialización de una identidad misionerista, es la que derivo en el viraje respecto a las percepciones de la polémica megaconstrucción, devenida ahora en la expresión de unión, pero no cualquier unión, sino una unión que tiene como impulsora a Yacyretá.

\section{Bibliografia}

BAUMAN, Zygmund. Modernidad Líquida. Buenos Aires: Fondo de Cultura Económica, 2000.

BRITES, Walter. Acción colectiva, movilización y protesta de los desplazados por la Represa Yacyretá. La construcción de demandas reivindicativas en territorios de relegación. Posadas, Facultad de Humanidades y Ciencias Sociales, Universidad Nacional de Misiones, (UNaM), 2012. Pp. 1 - 304. (Tesis en Doctorado en Antropología Social).

BRITES, Walter. La mega-hidroeléctrica Yacyretá en el vórtice de las reconfiguraciones urbanas. El caso de las ciudades de Posadas, Argentina y Encarnación, Paraguay. URBS. Revista de Estudios Urbanos y Ciencias Sociales, v. 4, n.2, p. 91-107, 2014. Disponible en: <http://www2.ual.es/urbs/index.php/urbs/article/view/brites>.

BRITES, Walter. ¿Ciudades gemelas? Posadas, Argentina y Encarnación, Paraguay en perspectiva sociourbana. [Twin cities? Posadas, Argentina and Encarnación, Paraguay in socio-urban perspective]. Estudios Fronterizos, 19, pp. 1-26, 2018. Disponible en: e020.doi:https://doi.org/10.21670/ref.1820020.

CARBONARI, María Rosa. ¿Quién construye la historia? La rehabilitación de los sujetos y la biografía renovada. Mendoza, Facultad de Filosofía y Letras, Universidad Nacional de Cuyo, 2003. pp. 20 - 57 (II Congreso Interoceánico de Estudios Latinoamericanos). Disponible en: «http://ffyl.uncuyo.edu.ar/revistas/index/7457».

CENICEROS, Melina. Paredes que hablan: la producción simbólica del espacio urbano a través del street art en Tijuana. Tijuana, México, Universidad Autónoma de Baja California, Colegio de la Frontera Norte. 2014. 159 p. (Tesis de Maestría en Estudios Culturales).

COSSI, Carla Antonella. Relaciones fluctuantes en los márgenes. La influencia de los proyectos de desarrollo y las políticas públicas en los flujos entre dos ciudades de frontera. 
Posadas, Facultad de Humanidades y Ciencias Sociales, Universidad Nacional de Misiones, (UNaM). 2014. 190 p. (Tesis de Maestría en Programa de Postgrado en Antropología Social).

COSSI, Carla Antonella. Procesos de integración- inserción/estigmatización-rechazo en ciudades de frontera, las condiciones laborales de los trabajadores transfronterizos en Posadas, Argentina y Encarnación, Paraguay". Posadas, Facultad de Humanidades y Ciencias Sociales, Universidad Nacional de Misiones (UNaM). 2017. Pp. 1 - 218 (Tesis de Doctorado en Programa de Postgrado en Antropología Social).

DOUGLASS, William R. Las Fronteras: ¿Muros o puentes? Revista Semestral "Historia y fuente oral", España, $\mathrm{N}^{\circ} 12$, Seminario de Historia Oral del Departamento de Historia Contemporánea, Universidad de Barcelona, pp. 43-50, 1994.

FERNANDEZ, Sandra. Más allá del territorio: la historia regional y local como problema. Discusiones, balances y proyecciones. Rosario: Prohistoria Ediciones, 2007.

CHIRIBOGA ZAMBRANO, Galo. Contrabando: Los rostros del contrabando, rutas fronterizas. Revista Perfil criminológico, Ecuador, FLACSO, Nro. 15, pp. 1-16. 2015.

JAUME, Fernando (comp.). Luchas por la hegemonía. Historias y etnografía en la Provincia de Misiones, Argentina. Posadas: EDUNAM (Editorial Universitaria de la Universidad Nacional de Misiones), 2017.

LEON, Osvaldo. Internet, derivaciones y paradojas. Revista América Latina en Movimiento, $\mathrm{N}^{\circ} 536$ "Redes sociales digitales, enredos y desenredos". 2018. ISSN 1390-1230.

LINARES, María Dolores. Un puente en la zona transfronteriza: representaciones sociales, identidades y conflicto. El caso Posadas-Encarnación. Revista Estudios fronterizos, Mexicali, vol. 10, págs. $47-77.2009$.

OROZCO, Guillermo. Medios, audiencias y mediaciones. Revista Comunicar, España, $\mathrm{N}^{\circ} 8$, pp. 25-30. 1997. Disponible en: «http://www.redalyc.org/pdf/158/15800806.pdf».

OVIEDO, Norma. Relaciones comerciales y conflictos fronterizos. Siglo XIX, Misiones en la red platina. Posadas, EDUNaM (Editorial Universitaria de la Universidad Nacional de Misiones), 2014.

OVIEDO, Norma y ARELLANO. Territorialidades vividas, dinámicas fronterizas en la región misionera. Dossier, Revista Intellector, CENEGRI (Centro de Estudos em geopolítica \& relacoes internacionais), v. 13, n. 26, 2017. Disponible en: «http://www.cenegri.org.br/intellector/ojs2.4.3/index.php/intellector/issue/view/27/showToc».

VEZZETTI, Hugo. Pasado y presente: Guerra, dictadura y sociedad en la Argentina. Buenos Aires: Siglo XXI. 2003.

WOLF, Eric. Introducción. En: Europa y la gente sin historia. Buenos Aires: Fondo de Cultura Económica, 1987. 


\section{Fuentes}

\section{Sitios Oficiales}

MINISTERIO DEL INTERIOR. Argentina - Centros de Frontera. Disponible en: «http://fronteras.dnm.gov.ar/centros [enero 2020]».

ENTIDAD BINACIONAL YACYRETA. Disponible en: «https://www.eby.org.ar/[enero 2020]».

PLATAFORMA VIRTUAL CHANGE ORG. Petición de firmas "Detengan la construcción del muro que divide Argentina y Paraguay" 2015. Disponible en: «https://www.change.org/p/obrasdeyacyreta-detengan-la-construcci\%C3\%B3n-del-muropara-dividir-argentina yparaguay?recruiter=69676949\&utm_source=share_petition\&utm_medium=twitter\&utm_ca mpaign=share_twitter_responsive [febrero 2020]».

TWITTER GUINNESS WORLD RECORDS witter Guinness «@gwr_es». Disponible en: «https://twitter.com/gwr_es/status/1185744139167686661?ref_src=twsrc\%5Etfw\%7Ctwcamp \%5Etweetembed\%7Ctwterm\%5E1185744139167686661\&ref_url=https\%3A\%2F\%2Fwww. noticiasdel6.com\%2Fmural-de-posadas-recibio-el-titulo-record-por-el-mural-dibujado-alapiz-mas-grande-del-mundo\%2F [enero 2020]».

\section{Audiovisual}

DOCUMENTAL "El mural más grande del mundo", octubre 2019. Disponible en: « https://www.youtube.com/watch?v=MyFPY6nmrR8».

\section{Artículos Periodísticos}

"La EBY defiende el muro de frontera: 'Nos pedían que hagamos un alambrado'. Misiones Online, Posadas, 2015. Disponible en: https://misionesonline.net/2015/08/19/la-eby-defiendesu-polemico-muro-de-frontera-nos-pedian-que-hagamos-un-alambrado/ [enero 2020]).

"Mentiras y verdades sobre el polémico muro". Por nuestra redacción regional. ABC color, Paraguay, Agosto 2015. Disponible en: http://www.abc.com.py/nacionales/medias-verdadesen-cuestionamientos-a-muro-en-la-costanera-de-posadas-1399910.html. [enero 2020].

"Comenzarán a demoler parte del muro para construir nuevos accesos". El territorio, Diario online, julio 2017. Disponible en https://www.elterritorio.com.ar/comenzaran-a-demolerparte-del-muro-para-construir-nuevos-accesos-2491950965971657-et [enero 2020].

"Posadas-Encarnación, el muro argentino" por Gayetzky Graciela de Kuna. Clarín ARQ, Sección arquitectura urbano, febrero, 2017. Disponible en: https://www.clarin.com/arq/urbano/posadas-encarnacion-muro-argentino_0_H1GPeHKe.html [enero 2020].

"El mural más grande del mundo", Entidad Binacional Yacyretá, 2019. Disponible en: https://www.eby.org.ar/el-mural-mas-grande-del-mundo/[enero 2020]. 
"Posadas: entregaron el título récord por el mural dibujado a lápiz más grande del mundo". El Territorio, 2019. Disponible en: https://www.elterritorio.com.ar/posadas-entregaron-el-titulorecord-por-el-mural-dibujado-a-lapiz-mas-grande-del-mundo-47244-et [febrero 2020].

"Mural de Posadas recibió el título récord por la superficie dibujada a lápiz más grande del mundo". Noticias del 6, 2019. Disponible en: https://www.noticiasdel6.com/mural-deposadas-recibio-el-titulo-record-por-el-mural-dibujado-a-lapiz-mas-grande-del-mundo/[enero 2020].

"El mural hecho a lápiz más grande del mundo" por Sánchez Luisa. Guinnes World Records, Página Oficial, sección noticias, 2019. Disponible en: https://www.guinnessworldrecords.es/news/corporate/2019/11/el-mural-hecho-a-lapiz-masgrande-del-mundo-esta-en-posadas-argentina [enero 2020]).

\section{Biografia da Autora}

Ana Belén Medina - Becaria de investigación. Proyecto 16H453 denominado "Relaciones de poder: Misiones como problema historiográfico. Entre lo local y lo regional" bajo la dirección de la Mgter. Norma Oviedo. Secretaria de Investigación, Facultad de Humanidades y Ciencias Sociales, Universidad Nacional de Misiones. Estudiante avanzada del Profesorado y Licenciatura en Historia. Correo electrónico: medinapirada@gmail.com 